\title{
Preparation, characterization and evaluation of solid lipid nanoparticles and niosomes for ING4 gene delivery to MCF-7 cells
}

\author{
Uğur KARAGÖZ 1,2 (D), Ayşe Gülten KANTARCI ${ }^{1 *}$ \\ 1 Department of Pharmaceutical Biotechnology, Faculty of Pharmacy, Ege University, İzmir, Turkey. \\ 2 Department of Pharmaceutical Biotechnology, Faculty of Pharmacy, Marmara University, Haydarpaşa 34668 \\ İstanbul, Turkey. \\ * Corresponding Author. E-mail: gulten.kantarci@ege.edu.tr (A.G.K.); Tel. +90-232-311 2575.
}

Received: 06 May 2019 / Revised: 15 June 2019 / Accepted: 10 July 2019

\begin{abstract}
In this study, we aimed to develop lipid-based delivery systems for ING4 gene. For this purpose, we chose solid lipid nanoparticle (SLN) and niosome formulations for their advantages in several ways. SLNs were prepared via hot microemulsion method with slight modifications. Niosomes were prepared by using thin film hydration method. Both of those formulations contain cationic lipids for the purpose of gaining positive charge. Thus, complexation with ING4 gene carrier plasmid DNA is conducted via electrostatic interactions. DLS measurements showed us both of those formulations have appropriate zeta potential for complexation which is above $30 \mathrm{mV}$. Average particle size of SLNs is $9.76 \pm 0.13 \mathrm{~nm}$. Vesicle size of niosomes is $483.2 \pm 20.19 \mathrm{~nm}$. Both of those formulations can be considered nano-sized delivery systems. Reliability of those values were supported with TEM imaging. DNA protection ability of those formulations were observed in serum stability study. After characterization studies, cytotoxic effect of those delivery systems was evaluated on MCF-7 cell lines.
\end{abstract}

KEYWORDS: ING4; solid lipid nanoparticles; niosomes; gene delivery.

\section{INTRODUCTION}

Cells are basic units of human body. Cells grow and divide in a controllable manner when body needs more cells. When cells grow old or die, new cells replace them. However, cells start to grow in an uncontrollable manner when genetic mutations occur. This abnormal growth of cells is called cancer. There are more than 100 types of cancer including lung cancer, breast cancer, colorectal cancer and prostate cancer. According to worldwide cancer data, breast cancer is the second most common cancer type in humans and most commonly diagnosed cancer type in women worldwide [1-3].

Recent studies have shown that ING protein enhances p53 activity and regulates DNA repair, cell apoptosis and cell cycle processes [4]. ING4 has emerged as a tumor suppressor gene because its expression is downregulated in various cancer types. ING4 gene sequence is mutated or deleted in most of the cancer types including melanoma, ovarian cancer, lung cancer, breast cancer, colorectal cancer, gastric carcinoma, glioma, prostate cancer. ING4 was reported to suppress nuclear factor $\mathrm{kB}$ (NF-kB) signaling and mediate the transcriptional repression of multiple NF-kB-responsive genes, such as cyclooxygenase (Cox-2), hypoxiainducible factor 1a, matrix metalloproteinase 2 (MMP-2), MMP-9, CD34 (human hematopoietic stem cell membrane glycoprotein), interleukin 6 (IL-6), and IL-8, leading to angiogenesis inhibition in multiple malignancies. Therefore, these findings revealed that ING4 shows its tumor suppressive effects through multiple pathways. Previous studies showed that ING4 performed an important role in inhibiting tumor growth, promoting tumor apoptosis, recovering intercellular contact inhibition, affecting cell cycle progression and inhibiting tumor angiogenesis. In vitro experiments revealed that ING4 was abundantly expressed in normal tissues, but expression was significantly reduced in various malignant tumors [5-7]. For all the reasons mentioned above, researchers are seeking for different applications for ING4 protein.

Gene delivery means insertion a new gene to cells, generally for the purpose of treating a disease. It's a promising strategy in our era. However, its clinically limited due to its safety concerns. A successful gene

How to cite this article: Karagöz U, Kantarcı AG. Preparation, characterization and evaluation of solid lipid nanoparticles and niosomes for ING4 gene delivery to breast cancer cells. J Res Pharm. 2019; 23(5): 935-943. 
delivery depends on efficient delivery of genetic material to target cells and achieving gene expression in long term [8]. Viral gene delivery vectors, for example adenoviruses, could induce long term expression due to its chromosomal integration ability. Yet viral vectors have several concerns regarding safety, like the danger of insertional mutagenesis. Unlike viral vectors, non-viral delivery methods are safer, non-toxic, cheap, with low immunogenicity and producible in large batches [9].

Solid Lipid Nanoparticles (SLNs) are colloidal systems made of lipids that are solid in room temperature. They have similar ingredients with lipid nanoemulsions and liposomes. They all are lipid suspensions dispersed in water [10]. SLNs have lots of advantages compared to similar delivery systems: they don't show toxicity problems; they are biocompatible and producible in very small sizes $(10-1000 \mathrm{~nm})$; furthermore, they can be loaded with both hydrophobic and hydrophilic materials [11]. SLNs have proven record functioning as useful tools for nucleic acid delivery [12,13]. Due to its compatibility with cationic lipids, nucleic acids can be attached to SLNs via electrostatic interactions.

Niosomes are carrier systems like liposomes, except that non-ionic surfactants replace phospholipids of liposomes. Biggest advantage of niosomes compared to liposomes is that they are very cheap to produce. Also, they have chemical stability. Niosomes generally have 3 components; non-ionic surfactant, helper lipid (usually cholesterol) and cationic lipids [14,15]. While non-ionic surfactants generate micellar vesicles, helper lipids stabilize the structure. And cationic lipids are responsible for electrostatic interactions with negatively charged nucleic acids.

\section{RESULTS AND DISCUSSION}

\subsection{Construction of ternary phase diagram}

Titration for generating the ternary phase diagram was conducted in water jackets, shown in Figure 5, at $80^{\circ} \mathrm{C}$ which is at least $10^{\circ} \mathrm{C}$ above the lipids melting point. After generating phase diagram, a point was selected in green area to produce SLNs.

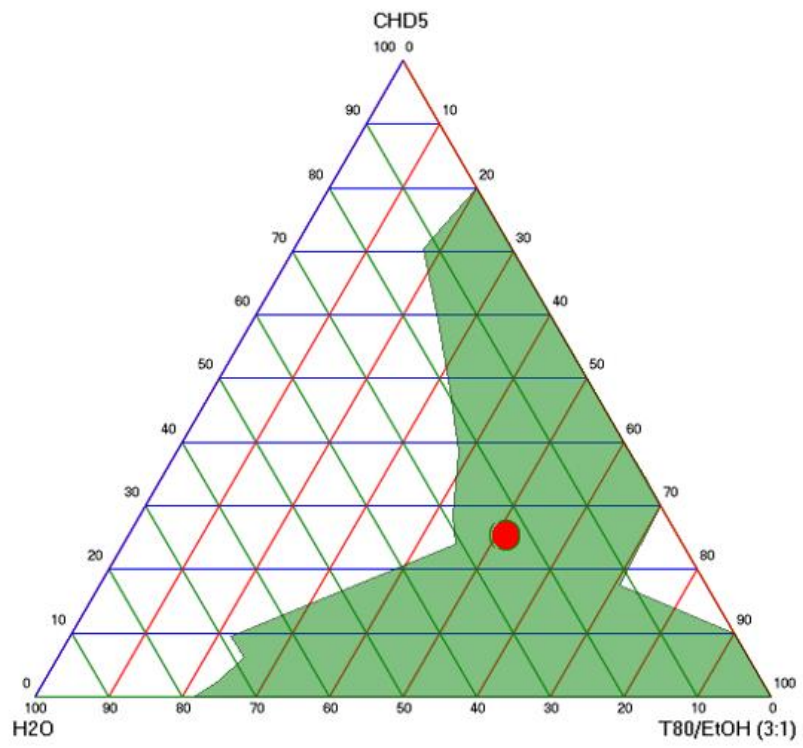

Figure 1. Ternary phase diagram that constructed with Compritol HD5 ATO (CHD5) as solid lipid, Tween 80/Ethanol (T80/EtOH) as Surfactant/Cosurfactant (S/Cos) and water $(\mathrm{H} 2 \mathrm{O})$. (Green area represents transparent $\mathrm{O} / \mathrm{W}$ (oil in water) microemulsion area. Red circle represents the center of the green area).

\subsection{Gel retardation assay}

Cationic SLN and Niosome formulations' complexation ability with pcDNA3.ING4 plasmid DNA were evaluated with gel retardation assay (Figure 2). As can be seen from the gel images, both SLN and Niosome formulations were retarded gradually as the amount of formulation increases. After the lane 6 (DNA:SLN \& DNA:Niosome : 1:1 (v/v)), both SLN and Niosome exhibited favorable DNA binding ability. Both of the formulations contain similar amount of cationic material and final dilutions are same as well. That could be the reason that they showed optimal complexation at the same value $(1: 1, \mathrm{v} / \mathrm{v})$. 

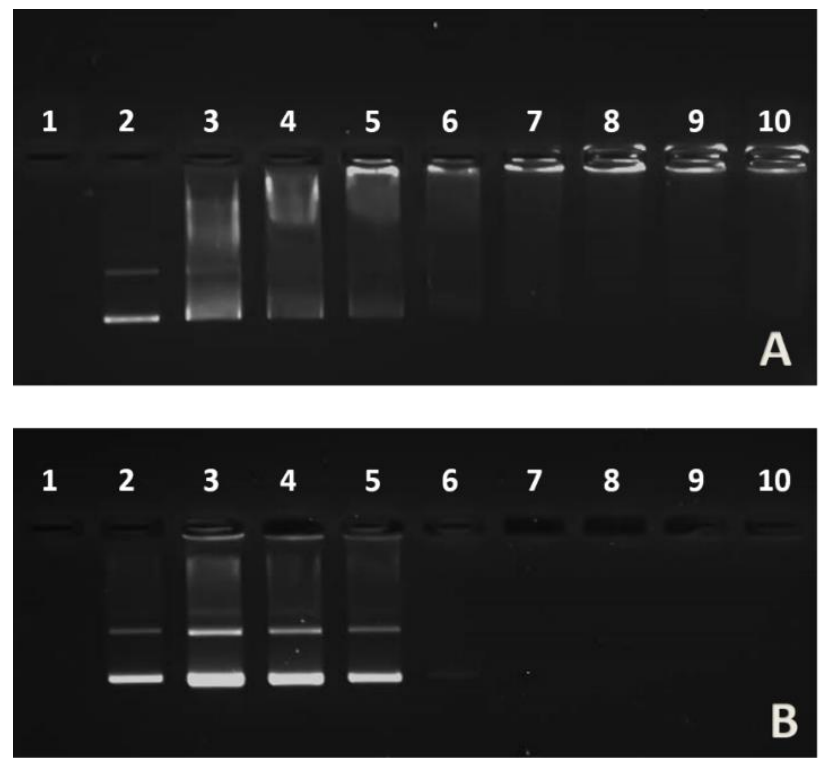

Figure 2. Agarose gel images of gel retardation assay. A: DNA:SLN complexes, B: DNA:Niosome complexes (1: Unloaded formulation as negative control, 2: Naked DNA as positive control, 3,4,5,6,7,8,9,10: DNA:SLN \& DNA:Niosome complexes for the ratio of 4:1, 3:1, 2:1, 1:1, 1:2, 1:3, 1:4, 1:5 (v/v), respectively).

\subsection{Dynamic light scattering (DLS) measurements}

DLS measurements were performed to investigate particle size and zeta potentials of formulations before and after the complexation with plasmid DNA. As can be seen from the results on Table 1, all formulations are in nanometer range. Particle size of SLN formulation increased from 9.8 to $65.5 \mathrm{~nm}$ after the complexation with DNA which was expected due to several DNA and SLN molecules attaching each other. As in SLNs, vesicle size increased from 483.2 to $504 \mathrm{~nm}$; zeta potential decreased from 64.5 to $59.9 \mathrm{mV}$ in niosome formulation. Decrease in zeta potential values can be explained with the negative charge of pcDNA3ING4 which was measured as $-7.32 \pm 5.35 \mathrm{mV}$. As a result, obtained net particle size and zeta potential values after the complexation procedure are sufficient for an efficient transfection [16].

Table 1. Particle size and zeta potential values of the formulations (before and after the complexation with DNA).

\begin{tabular}{lccc}
\hline & $\begin{array}{c}\text { Particle Size } \pm \text { SD } \\
(\mathbf{n m})\end{array}$ & PDI & $\begin{array}{c}\text { Zeta Potential } \pm \text { SD } \\
(\mathbf{m V})\end{array}$ \\
\hline SLN & $9.76 \pm 0.13$ & $0.42 \pm 0.00$ & $39.30 \pm 2.21$ \\
SLN:DNA (2.5:1) & $65.47 \pm 3.40$ & $0.71 \pm 0.06$ & $17.00 \pm 1.06$ \\
Niosome & $483.20 \pm 20.19$ & $0.25 \pm 0.20$ & $64.50 \pm 2.23$ \\
Niosome:DNA (1:1) & $503.90 \pm 14.80$ & $0.62 \pm 0.10$ & $59.90 \pm 2.50$ \\
\hline
\end{tabular}

\subsection{Serum stability study}

Serum stability study was conducted to investigate the DNA protection ability of formulations from serum nucleases. As can be seen in Figure 3A, naked DNA is degrading in the serum without any protection. Protection ability of SLNs and niosomes were observed in 24 hours periods at 3 different intervals of time (1, 6 and $24 \mathrm{~h}$ ). If we compare lane 1 (control DNA) with the others, it can be seen that the SLN formulation has protection ability in $10 \%$ FBS at only hour 1 (Figure 3B, lane 2). However, Niosome formulation has better serum protection than the SLNs. At any intervals of time and any FBS percentages that was tried, niosomes has full protection of DNA (Figure 3B-C-D, lanes 4-5). It has previously been discussed that, protection of pDNA against enzymes is not related with complexation efficiency entirely. Protection ability of DNA carrier systems against nucleases is associated with various physicochemical properties including particle size, zeta potential, surface structure and shape. These characteristics are probably determining the amount of plasmid DNA on the surface and exposure of DNA to nucleases [17]. Therefore, high pDNA protection ability of niosomes against serum nucleases can be explain with their high zeta potential and vesicle size properties. 

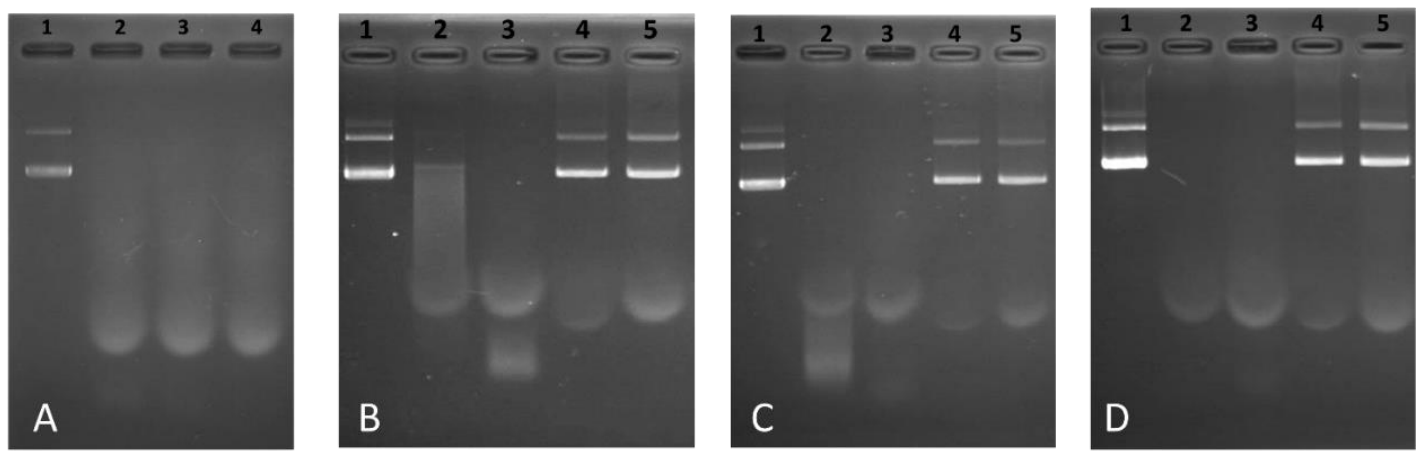

Figure 3. Agarose gel images of serum stability study. A: DNA without formulation (1: naked DNA, 2 : DNA+10\% FBS 1h, 3: DNA+10\% FBS 6h, 4: DNA+10\% FBS 24h), B-C-D: 1-6-24 hours (1: naked DNA, 2: SLN:DNA+10\% FBS, 3: SLN:DNA+50\% FBS, 4: Niosome:DNA+10\% FBS, 5: Niosome:DNA+50\% FBS)

\subsection{XTT cell proliferation assay}

Naked pDNAs and formulations were tested on MCF-7 cells for evaluation of their cytotoxic effects (Figure 4). As can be seen in the Figure 4 on the left, no significant difference was found between pcDNA3 and pcDNA3-ING4 $(\mathrm{p}>0,05)$.

Unloaded niosome formulation and pcDNA3 loaded Niosomes have proliferative effect at $5 \mu 1$ dose. This effect may be caused by the nutrition ability of cholesterol present in the formulations. Niosome formulation contains fair amount of cholesterol. Previous literatures reported that cholesterol has the ability of supporting cell growth in mammalian cells [18]. Among the pcDNA3.ING4 treatment groups of niosome formulation, $5 \mu 1$ dose has the best effect as compared to other doses. Statistical analysis supports that finding $(p<0,001)$. At $10 \mu l$ dose, viability remained between $70-90 \%$ with no statistically significant difference $(p>0,05)$.

As unloaded SLNs and pcDNA3 loaded SLNs displayed low toxicity at 2 and $5 \mu 1$ doses, they can be considered suitable for application at these doses. The antiproliferative effect of pcDNA3.ING4 loaded SLNs is statistically significant compared to pcDNA3 loaded SLNs at these dose $(99 \%$ vs. $70 \%$ for $2 \mu 1$ dose $p<0,05$, and $89 \%$ vs. $57 \%$ for $5 \mu 1$ dose $\mathrm{p}<0,05)$.

In both Niosomes and SLNs, toxic effect was observed at higher amounts. It is a well-known fact that highly charged nanoparticles may cause cytotoxicity by disruption the cell membrane [19]. Cationic charge of our formulations decreased after complexation according to Table 1. Unloaded niosomes and SLNs have higher toxicity than the pDNA loaded formulations at high doses according to Figure 4 which supports the aforementioned statement.
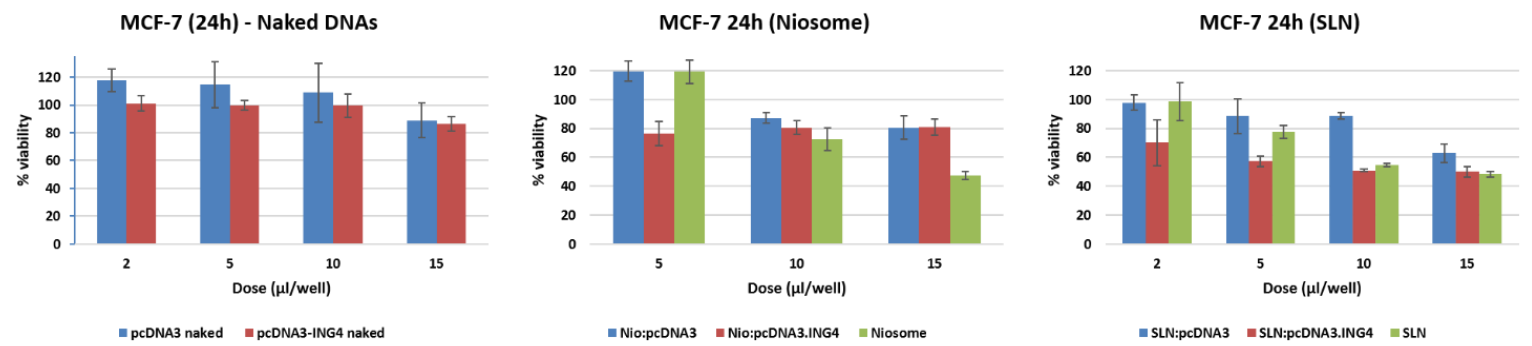

Figure 4. Cell viabilities of MCF-7 cells that treated with pcDNA3 control DNA, pcDNA3.ING4 therapeutic DNA, Niosomes, SLNs and complexes.

\subsection{Morphology of SLNs and niosomes}

Morphologic structure of SLNs and niosome vesicles are observed with high contrast electron microscopy (Figure 5). TEM images shoved that both SLNs and niosomes has spherical structure, and their sizes are in nanometer range which is supporting the DLS measurements (Table 1). 

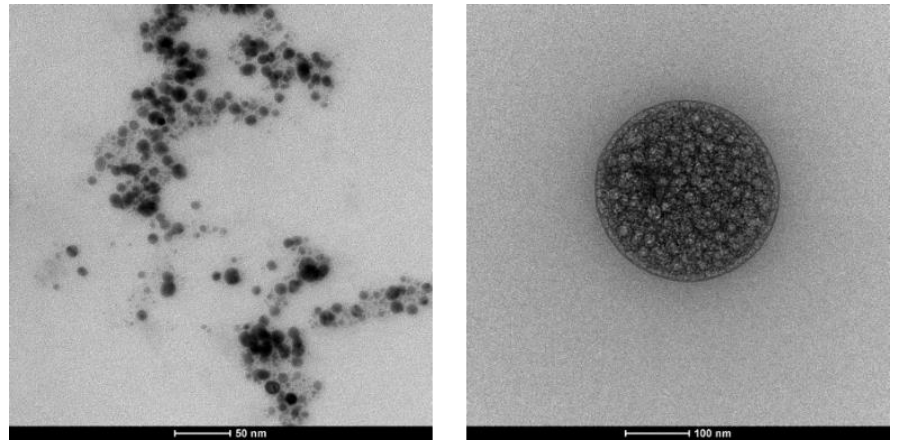

Figure 5. TEM images of SLNs (on the left) and niosomes (on the right).

\subsection{Stability of SLNs and Niosomes}

Particle size and zeta potential values of SLNs and Niosomes were measured at 1st, 30th, 45th and 60th days following the preparation of formulations. Results were given in Table 2. As can be seen from the measurement results, particle sizes of SLNs are stable for a period of two months. There is a slight decrease in zeta potential with time. However, particle size and zeta potential values can be considered adequate for complexation with plasmid DNA within 45 days. As for the niosomes, they are unstable due to the increase in vesicle size. Vesicle size of the prepared niosomes increases dramatically with time. However, they retain their original vesicle size if the sonication step is repeated. As can be seen from the Table 2, there is no significant change in their zeta potential values. Nevertheless, it can be said that SLNs are more suitable for long term storage due to their particle size stability.

Table 2. Particle size and zeta potential stability of SLNs and Niosomes (PS: particle size (nm), VS: vesicle size (nm), ZP: zeta potential (mV), SD: standard deviation).

\begin{tabular}{ccccc}
\hline \multirow{2}{*}{ Day } & \multicolumn{3}{c}{ SLNs } & Niosomes \\
\cline { 2 - 5 } & PS \pm SD & ZP \pm SD & VS \pm SD & ZP \pm SD \\
\hline $\mathbf{1}$ & $9.76 \pm 0.13$ & $39.30 \pm 2.21$ & $483.20 \pm 20.19$ & $64.50 \pm 2.23$ \\
30 & $11.61 \pm 0.16$ & $26.60 \pm 2.46$ & $1563.00 \pm 79.19$ & $70.10 \pm 2.47$ \\
45 & $9.77 \pm 0.09$ & $26.20 \pm 1.86$ & $1529.00 \pm 149.10$ & $65.60 \pm 1.19$ \\
60 & $11.97 \pm 0.22$ & $13.20 \pm 1.92$ & $2321.00 \pm 305.70$ & $65.50 \pm 0.67$ \\
\hline
\end{tabular}

\section{CONCLUSION}

In this study, we focused on development of novel SLN and niosome formulations for ING4 delivery. Both formulations developed in this study have appropriate size and zeta potential for plasmid DNA delivery. TEM images of SLNs and Niosomes shows that they have spherical shape and nanometer ranged sizes. Niosomes have better serum stability than the SLNs. Cell culture studies have shown that both formulations have cytotoxic effect at certain doses on MCF-7 cell line when they were complexed with pcDNA3.ING4 while they are non-toxic when complexation is performed with pcDNA3 control DNA. Naked DNAs has no significant effect on viability according to XTT cell proliferation assay. As a result, it can be concluded that the developed SLNs and Niosomes are candidate carrier systems for plasmid DNA delivery.

\section{MATERIALS AND METHODS}

\subsection{Materials}

pcDNA3-ING4 plasmid was purchased from Addgene as a bacterial stab (USA). pcDNA3 plasmid DNA was kindly given as a gift by Prof. Dr. Zeki Topçu (Ege University, Faculty of Pharmacy, Pharmaceutical Biotechnology Dept., Izmir, Turkey). Compritol HD5 ATO was a gift sample from Gattefose (France). DDAB was purchased from TCI (Japan). DMEM F12, FBS, and XTT cell proliferation kits were purchased from Biological Industries (USA). Esterquat-1 was purchased from Gerbu Biotechnik (Germany). Chloroform, SDS, Span 80 and Tween 80 were purchased from Sigma Aldrich (Germany). PBS tablets were purchased from Applichem (Germany). 


\subsection{Methods}

\subsubsection{Preparation of SLNS}

SLNs were prepared by using hot microemulsion technique with slight modifications [20]. Briefly, Compritol HD5 ATO was used as a solid lipid, DDAB and Esterquat-1 were used as cationic lipids, tween 80 and Ethanol were used as Surfactant/Cosurfactant mixture. After generating ternary phase diagram, optimal formulations were selected for addition of cationic lipids. The amount of added cationic lipids were reduced from solid lipid amount. Final volume of dilution to generate nanoparticles was 1:10 (Microemulsion:UP water). Final composition of the SLN formulation was given in Table 3. SLN preparation is represented schematically in Figure 6.

Table 3. Composition of SLN formulation.

\begin{tabular}{lc}
\hline Material & Final percentage of material (\%) \\
\hline Compritol HD5 ATO & 7.5 \\
Surfactant/Cosurfactant (3/1) & 30 \\
Esterquat-1 & 2 \\
DDAB & 0.5 \\
Ultra-Pure Water & 60 \\
\hline
\end{tabular}
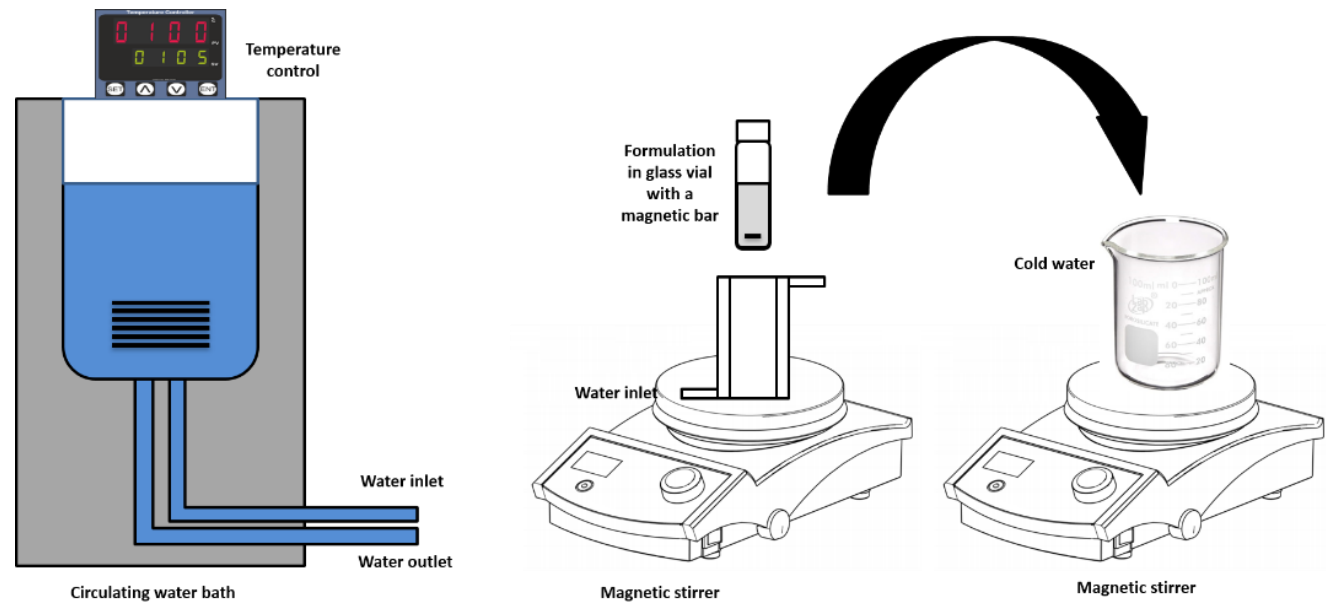

Figure 6. Schematic representation of SLN preparation.

\subsubsection{Preparation of Niosomes}

Niosomes were prepared with thin film hydration method [21,22]. Briefly, Span 80, cholesterol and DDAB were weighed accurately at molar ratio of 6:2:2 in a $50 \mathrm{~mL}$ round bottom flask. Mixture was dissolved in $10 \mathrm{~mL}$ chloroform. Organic solvent was slowly evaporated at $55^{\circ} \mathrm{C}$ under vacuum, using rotary evaporator (Heidolph 4000, Germany). Remnants of chloroform were removed with nitrogen. The dried film on the inner side of round bottom flask was hydrated with $10 \mathrm{~mL}$ PBS (pH:7.4). Final dispersion was sonicated for 3 mins in a bath sonicator to obtain small sized vesicles (Elmasonic E100, Germany). Niosome preparation is represented schematically in Figure 7.

\subsubsection{DLS Measurements}

Dynamic Light Scattering measurements were performed with Malvern Zetasizer Nano ZS (Malvern Instruments Ltd., UK). Scattering angle was $173^{\circ}$ for particle size measurements. Zeta cuvettes were used for zeta potential measurements. Zeta potential was calculated by a software using Smoluchowski equation. Three measurements were conducted for each sample.

\subsubsection{Complexation with Plasmid DNA}

Complexation between cationic formulations and negative charged Plasmid DNA occurred via electrostatic interactions. Complexation efficiency of formulations were evaluated with gel retardation assay $[23,24]$. Different volumes of formulations and DNA solution were mixed and vortexed at $25^{\circ} \mathrm{C}$ for 30 minutes. 
Then complexes were applied to $1 \%$ agarose gel electrophoresis in Tris-acetate-EDTA buffer (100 V, $30 \mathrm{~min})$. DNA bands were detected via EtBr staining. Agarose gel photographs were taken with UV transilluminator. DNA stock solution was $100 \mu \mathrm{g} / \mathrm{ml}$.

Optimized complexation ratios for SLNs were 2.5:1 (SLN:DNA), and 1:1 (Niosome:DNA) for niosomes (v/v).

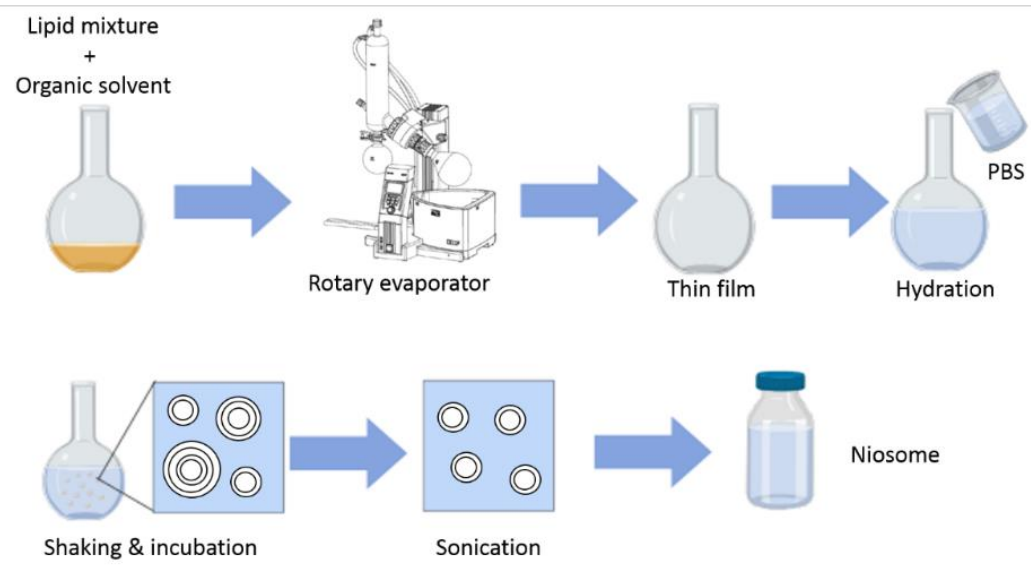

Figure 7. Schematic representation of Niosome preparation.

\subsubsection{In Vitro Serum Stability}

Protection of complexed DNA against serum was evaluated with serum stability study at $37^{\circ} \mathrm{C} .10 \%$ and $50 \%$ fetal bovine serum was used for 1, 6 and 24-hour intervals. At the end of the incubation times, 0,5 M EDTA with Proteinase K was used as a reaction inhibition solution. Then, integrity of DNA was evaluated with agarose gel electrophoresis.

\subsubsection{XTT cell proliferation assay}

MCF-7 human breast cancer cell line was used for evaluation of the efficiency of our delivery systems. Cells were cultured in DMEM F12 medium supplemented with $10 \%$ FBS and $100 \mathrm{U} / \mathrm{mL}$ penicillin/streptomycin. Cells were grown in humidified atmosphere with $5 \% \mathrm{CO}_{2}$ at $37^{\circ} \mathrm{C}$.

Cells were seeded on 96 well plates at a concentration of 10000 cells/well and incubated for 24 hours before transfection. Then, formulations were added in specified amounts. After incubation time, cells were washed with PBS and XTT reagent applied according to manufacturer's instructions. Non-treatment cells are considered $100 \%$ viable in calculations. All treatment groups were in triplicates.

\subsubsection{TEM Imaging}

Morphology of prepared SLNs and Niosomes was investigated with FEI Tecnai G2 high contrast transmission electron microscope (FEI Co., USA). $10 \mu \mathrm{L}$ of samples were placed on carbon coated 200 mesh copper grids and allowed to dry overnight at $25^{\circ} \mathrm{C}$. Imaging was carried out at $120 \mathrm{kV}$.

\subsubsection{Stability of SLNs and Niosomes}

Particle size and zeta potential stability of prepared SLNs and Niosomes were investigated with DLS measurements at several time intervals (Malvern Zetasizer Nano ZS, Malvern Instruments Ltd., UK). Formulations were stored in $4^{\circ} \mathrm{C}$ in this period.

\subsubsection{Statistical Analysis}

Statistical analysis was performed using GraphPad Prism 6.0. Cell culture results were analyzed with Student's t-test, and $\mathrm{p}<0,05$ value was considered as statistically significant. 
Acknowledgements: This study was supported by the Scientific Research Fund of Ege University (project No: 16ECZ025).

Author contributions: Concept - U.K., A.G.K.; Design - U.K., A.G.K.; Supervision - A.G.K.; Resources - A.G.K.; Materials - U.K., A.G.K.; Data Collection and/or Processing - U.K.; Analysis and/or Interpretation - U.K., A.G.K.; Literature Search - U.K., A.G.K.; Writing - U.K., A.G.K.; Critical Reviews - U.K., A.G.K.

Conflict of interest statement: The authors declared no conflict of interest.

\section{REFERENCES}

[1] Siegel RL, Miller KD, Jemal A. Cancer statistics, 2019. Ca-Cancer J Clin. 2019; 69(1): 7-34. [CrossRef]

[2] Chang L, Weiner LS, Hartman SJ, Horvath S, Jeste D, Mischel PS, Kado DM. Breast cancer treatment and its effects on aging. J Geriatr Oncol. 2019; 10(2): 346-355. [CrossRef]

[3] Ju J, Zhu A-J, Yuan P. Progress in targeted therapy for breast cancer. Chronic Dis Transl Med. 2018; 4(3): 164-175. [CrossRef]

[4] Wei Q, He W, Lu Y, Yao J, Cao X. Effect of the tumor suppressor gene ING4 on the proliferation of MCF-7 human breast cancer cells. Oncol Lett. 2012; 1(10): 438-442. [CrossRef]

[5] Pan X, Wang R, Bian H, De W, Zhang P, Wei C, Wang Z. Overexpression of inhibitor of growth 4 enhances radiosensitivity in non-small cell lung cancer cell line SPC-A1. Technol Cancer Res Treat. 2017; 16(5): 533-545. [CrossRef]

[6] Shao B, Liu E. Expression of ing4 is negatively correlated with cellular proliferation and microvessel density in human glioma. Oncol Lett. 2017; 14(3): 3663-3668. [CrossRef]

[7] Cui S, Gao Y, Zhang K, Chen J, Wang R, Chen L. The emerging role of inhibitor of growth 4 as a tumor suppressor in multiple human cancers. Cell Physiol Biochem. 2015; 36(2): 409-422. [CrossRef]

[8] Solinís MÁ, Del Pozo-Rodríguez A, Apaolaza PS, Rodríguez-Gascón A. Treatment of ocular disorders by gene therapy. Eur J Pharm Biopharm. 2015; 95: 331-342. [CrossRef]

[9] Madkhali O, Mekhail G, Wettig SD. Modified gelatin nanoparticles for gene delivery. Int J Pharm. 2019; 554: 224-234. [CrossRef]

[10] Trucillo P, Campardelli R. Production of solid lipid nanoparticles with a supercritical fluid assisted process. J Supercrit Fluid. 2019; 143: 16-23. [CrossRef]

[11] Dara T, Vatanara A, Meybodi MN, Vakilinezhad MA, Malvajerd SS, Vakhshiteh F, Shamsian A, Sharifzadeh M, Kaghazian H, Mosaddegh MH. Erythropoietin-loaded solid lipid nanoparticles: Preparation, optimization, and in vivo evaluation. Colloids Surf B. 2019; 178: 307-316. [CrossRef]

[12] Fàbregas A, Sánchez-Hernández N, Ticó JR, García-Montoya E, Pérez-Lozano P, Suñé-Negre JM, Hernández-Munain C, Suñé C, Miñarro M. A new optimized formulation of cationic solid lipid nanoparticles intended for gene delivery: Development, characterization and DNA binding efficiency of TCERG1 expression plasmid. Int J Pharm. 2014; 473(12): 270-279. [CrossRef]

[13] Carrillo C, Sánchez-Hernández N, García-Montoya E, Pérez-Lozano P, Suñé-Negre JM, Ticó JR, Suñé C, Miñarro M. DNA delivery via cationic solid lipid nanoparticles (SLNs). Eur J Pharm Sci. 2013; 49(2): 157-165. [CrossRef]

[14] Ojeda E, Puras G, Agirre M, Zarate J, Grijalvo S, Eritja R, Digiacomo L, Caracciolo G, Pedraz JL. The role of helper lipids in the intracellular disposition and transfection efficiency of niosome formulations for gene delivery to retinal pigment epithelial cells. Int J Pharm. 2016; 503(1-2): 115-126. [CrossRef]

[15] Moghassemi S, Hadjizadeh A. Nano-niosomes as nanoscale drug delivery systems: An illustrated review. J Control Release. 2014; 185(1): 22-36. [CrossRef]

[16] Yadav N, Kumar N, Prasad P, Shirbhate S, Sehrawat S, Lochab B. Stable Dispersions of Covalently Tethered Polymer Improved Graphene Oxide Nanoconjugates as an Effective Vector for siRNA Delivery. ACS Appl Mater Interfaces. 2018; 10(17): 14577-14593. [CrossRef]

[17] Sheikhsaran F, Sadeghpour H, Khalvati B, Entezar-Almahdi E, Dehshahri A. Tetraiodothyroacetic acid-conjugated polyethylenimine for integrin receptor mediated delivery of the plasmid encoding IL-12 gene. Colloids Surf B. 2017; 150: 426-436. [CrossRef]

[18] Xu F, Rychnovsky SD, Belani JD, Hobbs HH, Cohen JC, Rawson RB. Dual roles for cholesterol in mammalian cells. Proc Natl Acad Sci USA. 2005; 102(41): 14551-14556. [CrossRef] 
[19] Fröhlich E. The role of surface charge in cellular uptake and cytotoxicity of medical nanoparticles. Int J Nanomedicine. 2012; 7: 5577-5591. [CrossRef]

[20] Kotmakçı M, Akbaba H, Erel G, Ertan G, Kantarcı G. Improved method for solid lipid nanoparticle preparation based on hot microemulsions: Preparation, characterization, cytotoxicity, and hemocompatibility evaluation. AAPS Pharm Sci Tech. 2017; 18(4): 1355-1365. [CrossRef]

[21] Pando D, Matos M, Gutiérrez G, Pazos C. Formulation of resveratrol entrapped niosomes for topical use. Colloids Surf B. 2015; 128: 398-404. [CrossRef]

[22] Abdelbary AA, Aboughaly MHH. Design and optimization of topical methotrexate loaded niosomes for enhanced management of psoriasis: Application of Box-Behnken design, in-vitro evaluation and in-vivo skin deposition study. Int J Pharm. 2015; 485(1-2): 235-243. [CrossRef]

[23] Han H, Chen W, Yang J, Liang X, Wang Y, Li Q, Yang Y, Li K. Inhibition of cell proliferation and migration through nucleobase-modified polyamidoamine-mediated p53 delivery. Int J Nanomedicine. 2018; 13: 1297-1311. [CrossRef]

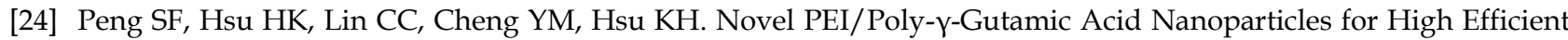
siRNA and Plasmid DNA Co-Delivery. Molecules. 2017; 22-86. [CrossRef]

This is an open access article which is publicly available on our journal's website under Institutional Repository at http://dspace.marmara.edu.tr. 